health centres. Moreover, the public awareness and prevention campaigns run by the staff of these centres within the community are not organised as part of any structured framework, and are not officially planned or monitored.

There are plans to strengthen the patient associations by improving their structure and increasing contact with the umbrella organisations, professional associations and the institutions engaged in defending the rights of patients facing discrimination. Opportunities for social entrepreneurship are also being explored. Given that individuals with mental disorders tend to adopt higher-risk lifestyles, awareness campaigns regarding tobacco and alcohol consumption and balanced nutrition will also be run within the associations.
It is hoped that the process adopted for the reforms of mental health services in Bosnia and Herzegovina will be applied in other Eastern European countries to move from institutional care to community-based approaches.

\section{References}

Bowers M. E. \& Yehuda R. (2016) Intergenerational transmission of stress in humans. Neuropsychopharmacology, 41(1), 232-244.

Devakumar D., Birch M., Osrin D., et al (2014) The intergenerational effects of war on the health of children. BMC Medicine, 12, 57.

Jordanova K. (2012) Transmission of traumatic experiences in the families of war survivors from Bosnia and Herzegovina. Contemporary Issues, 5(1), 52-60.

Priebe S., Bogic M., Ajdokovic D., et al (2010) Mental disorders following war in the Balkans: a study in 5 countries. Archives of General Psychiatry, 67(5), 518-528.

\title{
SPECIAL PAPER \\ Bearing the cost of the American dream: reflecting on street homelessness in America
}

\author{
Parashar P. Ramanuj
}

Consultant Liaison Psychiatrist, Royal National Orthopaedic Hospital, London, UK; email p.ramanuj@doctors.org.uk

Conflicts of interest. This reflection was based on my time spent in America as a 2015/2016 Harkness Fellow in Health Care Policy and Practice. The

Fellowship is administed by The

by The

Commonwealth Fund, a private

independent foundation based in New York City. The views pre-

sented here are my own and not necessarily those of The

Commonwealth Fund, its direc-

Coms, officers or stuff. This mant

This manu-

script developed from a talk given

to the UK Harkness Alumni

Association at the Health

Foundation in London.

Acknowledgements. I thank the reviewer and Dr Howard Ryland, Mr Luke O'Shea and Prof George Ikkos for their helpful comments on earlier drafts of this

manuscript.

doi:10.1192/bji.2017.32
This paper is a British psychiatrist's personal reflection of the treatment of homeless people in American societies. Drawing upon theories of social distance, exclusion, discrimination and internalised stigma, this reflective piece suggests that homelessness is one price that certain societies pay to invest in the notion of individualised success and self-sufficiency. In reflecting on his own dissonance, the author argues that these societal processes exert a powerful influence on us as individuals, even if we as psychiatrists might think that our understanding confers on us a certain level of understanding.

For many, New York conjures up images of the Statue of Liberty, the Empire State Building and the bright lights and signs of Times Square. It does for me too; but having lived there for a year, mixed with these images are signs of a different nature. Some are pleas: 'I'm hungry and homeless. Please help.' Others, prayers: 'Hungry and Homeless. God Bless.' Some, simple parables: 'A good deed is rewarded.' Others still, reveal something of the person behind the sign: 'Cold and Hungry. Victim of domestic violence. 3 children.' And then there are those who need no written signs: those people who are ragged, dishevelled, mumbling, singing and dancing or glowering from sunken eyes but not quite seeing. I would see them every day on my way to work at the New York State Psychiatric Institute in upper Manhattan, on the subways and the streets, until I too stopped seeing.

\section{Un-seeing}

Homelessness has a broad meaning. Street homelessness refers to people who 'routinely find themselves on the street during the day with nowhere to go at night' (Diaz, 2006). It incorporates the term rough sleepers (people who sleep in the open air or places not designed for human habitation) as well as those who use temporary shelters, prisons and hospitals. Statistics on the number of rough sleepers are woefully inadequate, but best estimates suggest there were between 3000 and 4000 street homeless people in New York in 2016 (NYC Open Data, 2017). This is equivalent to the entire street homeless population of England for the same year (DCLG, 2016).

However, my epiphany came not in New York, but in Skid Row. This is one of the most impoverished areas of Los Angeles, with one of the greatest concentrations of street homeless people in America. I was visiting the (remarkable) Skid Row Housing Association, and my journey through the neighbourhood took me through street after street of simple tarpaulin tents with people in flagrant psychosis outside or intoxicated in the gutters. What was most astonishing was that 
(c) The Author 2018. This is an Open Access article, distributed under the terms of the Creative Commons AttributionNonCommercial-NoDerivatives licence (http://creativecommons. org/licenses/by-nc-nd/4.0/), which permits non-commercial re-use, distribution, and reproduction in ny medium, provided the original work is unaltered and is properly cited. The written permission of Cambridge University Press must be obtained for commercial re-use or in order to create a derivative work. this modern-day Gin Lane (Hogarth, 1751), resting in the shadow of that great reminder of the American dream - the Hollywood Hills, was just two blocks away from the decision makers of Downtown Los Angeles.

I returned to New York with new eyes. I remember watching the well-heeled Manhattanites walk past countless homeless people on the street without seeing them. The look of shock followed by repulsion (and then sometimes compassion) when one was forced to encounter a street homeless person (for example by requests for money) emphasised the un-seeing: a process akin to denial, a step beyond ignorance. During my training, I had worked in an assertive outreach team for the street homeless in south London, so these reactions were not new to me, but it was the scale of the un-seeing in America that was staggering.

\section{Seeing through a sociological lens}

Homeless people occupy a third space between physical proximity and social distance. They are what the early German sociologist Georg Simmel called the 'stranger': 'distance means that he, who is close by, is far, and strangeness means that he, who also is far, is actually near' (Simmel, 1950). Strangers may come into contact with society but they are excluded from it. Who could be more alienated than the homeless? They are the daily reminders of society's failures.

There is a strong dissonance in that statement: these are the people that have been failed by society, but they are also the people that society chooses to typecast as 'failures'. The tragedy is that homeless people have the additional perverse burden of bearing the blame for their own exclusion. Research in people with mental illness routinely shows that prior experience of discrimination leads individuals to expect discrimination and anticipate stigmatisation, which in turn can lead to a belief that stereotypes are warranted (Quinn et al, 2015). Similar pathways to internalised stigma have been described in homeless people (Belcher \& DeForge, 2012).

Stigma literally means a 'mark', and the more visible the mark, the stronger the stigmatisation. The homeless people that were most visible to me were those who were clearly psychotic or intoxicated. Within the population of homeless people, $20-35 \%$ have a diagnosable mental illness and the prevalence of psychotic illness and substance dependence is several magnitudes higher than in the general population (Rees, 2009). But social researchers make an interesting point: they believe in the correlation between mental illness and homelessness, but not in a direct link. When the prevalence of mental disorders among all classes of homeless people (for example, including homeless families) is compared with the domiciled poor people from the same geographical area in America, the rates are almost equivalent (Draine et al, 2002). Could the marginalisation of homeless people in society, and to a degree also those with mental illness, actually be evidence of a wider contempt for the poor?

\section{Seeing through a societal lens}

American society is infused with the idea that any person can achieve success given the right amount of ambition and dedication, i.e. that people get what they deserve. This is the American dream. It is a noble ideology, if only it were true: America has the least socially mobile economy in the high-income countries of the world (followed by the UK) (Corak, 2006). The story told by one homeless woman, Mary, reinforced the damaging gulf between the American dream and the true reason for her circumstances: sustaining permanent nerve damage in an industrial accident, she lost her job, her house and started living in her van. For Mary and many people who passed her by, she was to blame for what she did not have.

How we respond to homeless people can be seen as a reflection of how we respond to injustice generally. The need to believe in fairness is deeply ingrained in us; yet the world is a self-evidently unjust place. Decades of research has shown that, when faced with injustice, we will try to lessen it; but if we cannot do so, we will reassure ourselves that people deserve what they get. This is the flip side to the American dream. The classic experiment that postulated this 'justworld hypothesis' was conducted by Lerner and Simmons in the 1960s (Lerner \& Simmons, 1966). In it, people were shown a video of a woman receiving ever-increasing electric shocks. When given the option to stop her punishment, almost everyone did; but if not given this choice, the witnesses rationalised that she must have done something to deserve her torture. Her pain was the proof of her guilt, and so the fairness of the world was restored. Lerner and Simmons wrote 'the sight of an innocent person suffering without possibility of reward or compensation motivated people to devalue the attractiveness of the victim in order to bring about a more appropriate fit between her fate and her character'.

Several studies have related similar reactions to homelessness. Ten years ago, Toro et al (2007) found that America and the UK had the greatest lifetime prevalence of homelessness but spent the least on social welfare and had the least compassionate public attitudes to homeless people. Respondents from America in particular were most likely to endorse personal failings as an important cause of homelessness and the least likely to support increased federal spending to help homeless people. Contrary to expectations, exposure to socioeconomic inequality in unequal societies has been shown to reduce support for redistributive economic policies (Sands, 2017). Although both the UK and America share a 'special relationship' in terms of values, culture and socioeconomic factors; I think the ubiquity of street homeless people in America overwhelms 
the public's capacity to intervene and so justworld rationalisations are employed much more.

The American dream is a contract between society and the individual: where society will provide a level playing field on which, by working productively, the individual can achieve success. Homeless people are evidence that this contract is broken and the world is unjust, which is terrifying to a society that prizes individualism above other attributes. Projecting those fears onto another individual, who will then internalise them, is an effective collective defence. Homeless people bear the cost for the rest of America to believe in the dream.

\section{Perspective}

The moral challenge that homelessness represents applies equally to politicians, religious leaders, voluntary sector workers and healthcare professionals on both sides of the Atlantic. After all, the conservative notion of self-sufficiency and self-improvement in the UK uses similar justworld arguments as the American dream to explain social exclusion. Psychiatrists have a unique role to play in reframing the discourse around these powerful societal processes. There is a clear clinical need to better manage mental illness in the homeless population, irrespective of whether its prevalence is comparable to an equivalent domiciled poor population or not. Mental illness in homeless people acts synergistically with other medical and social illnesses. Psychiatrists, who are conversant in these complex interactions, are well placed to coordinate care for homeless people across multiple agencies and within multiple disciplines. Beyond the clinical and organisational considerations, as a profession we have a powerful voice and platform with which to achieve a different settlement for homeless people: one in which not just the quality of life of individuals but also decisions of equity and the cohesion of society as a whole need to be renegotiated. Ultimately, all people are not born equal, but equity is conferred upon us throughout our lives by the actions of others.

\section{References}

Belcher J. R. \& DeForge B. R. (2012) Social stigma and homelessness: the limits of social change. Journal of Human Behaviour in the Social Environment, 22, 929-946.

Corak M. (2006) Do poor children become poor adults? Lessons from a cross country comparison of generational earnings mobility. Research on Economic Inequality, 13, 143-188.

Department for Communities and Local Government (DCLG) (2016) Rough Sleeping Statistics Autumn 2016, England. Available at https:// www.gov.uk/government/statistics/

rough-sleeping-in-england-autumn-2016 (accessed 5 May 2017).

Diaz R. (2006) Shelter Factsheet: Street Homelessness. Shelter. Available at https://england.shelter.org.uk/__data/assets/pdf_file/ 0011/48458/Factsheet_Street_Homelessness_Aug_2006.pdf (accessed 5 May 2017).

Draine J., Salzer M. S., Culhane D. P., et al (2002) Role of social disadvantage in crime, joblessness, and homelessness among persons with serious mental illness. Psychiatric Services, 53, 565-573.

Hogarth W. (1751) Gin Lane. Etching and engraving on paper, $357 \times 305$ mm, Tate Collection, Tate Gallery.

Lerner M. J. \& Simmons C. H. (1966) Observer's reaction to the 'innocent victim': compassion or rejection? Journal of Personality and Social Psychology, 4, 203-210.

New York City Open Data (NYC Open Data) (2017). 311 Service Requests from 2010 to Present. Available at https://nycopendata. socrata.com/Social-Services/

311-Service-Requests-from-2010-to-Present/erm2-nwe9 (accessed 5 May 2017).

Quinn D. M., Williams M. K. \& Weisz B. M. (2015) From discrimination to internalized mental illness stigma: the mediating roles of anticipated discrimination and anticipated stigma. Psychiatric Rehabilitation Journal, 38, 103-108.

Rees S. (2009) Mental IIl Health in the Adult Single Homeless Population: A Review of the Literature. Public Health Resource Unit. Available at www.crisis.org.uk/data/files/publications/ (accessed 8 January 2017)

Sands M. L. (2017) Exposure to inequality affects support for redistribution. Proceedings of the National Academy of Sciences, 114, 663-668.

Simmel G. (1950) The sociology of Georg Simmel (Wolff, K., Trans. and Ed.). New York Free Press.

Toro P. A., Tompsett C. J., Lombardo S., et al (2007) Homelessness in Europe and the United States a comparison of prevalence and public opinion. Journal of Social Issues, 63, 505-524.

\title{
Evaluation of undergraduate psychiatric teaching in Sudan
}

\author{
Mohamed El Tahir, ${ }^{1}$ Abdelghani Elsheikh, ${ }^{2}$ Abdelrahman Abodoum ${ }^{3}$ and \\ Mohamed Hassan Ahmed ${ }^{4}$
}

Consultant Psychiatrist, Abertawe Bro Morgannwg University Health Board, Unansea, UK· email mohamed eltahir@wales.nhs.uk

${ }^{2}$ Consultant Psychiatrist, Medical Specialization Board, Khartoum, Sudan.
Development of an undergraduate psychiatric teaching programme and curriculum is a challenge in the current atmosphere of increasing knowledge and vast literature. However, the curriculum remains the cornerstone for future doctors' development and career. Doctors need to have the abilities to recognise, assess and manage common psychiatric conditions presenting at different levels of health services. This paper aims to 